\title{
Making sense: motor activation and action plausibility during sentence processing
}

\section{Kevin J. Y. Lam, Marcel C. M. Bastiaansen, Ton Dijkstra \& Shirley-Ann Rueschemeyer}

To cite this article: Kevin J. Y. Lam, Marcel C. M. Bastiaansen, Ton Dijkstra \& ShirleyAnn Rueschemeyer (2017) Making sense: motor activation and action plausibility during sentence processing, Language, Cognition and Neuroscience, 32:5, 590-600, DOI: 10.1080/23273798.2016.1164323

To link to this article: http://dx.doi.org/10.1080/23273798.2016.1164323

央 Published online: 20 Apr 2016.

Submit your article to this journal $\pi$

Џ Article views: 224

Q View related articles ¿

View Crossmark data ¿ᄌ 


\title{
Making sense: motor activation and action plausibility during sentence processing
}

\author{
Kevin J. Y. Lam ${ }^{a, b}$, Marcel C. M. Bastiaansen ${ }^{c, d}$, Ton Dijkstra ${ }^{a}$ and Shirley-Ann Rueschemeyer ${ }^{e}$

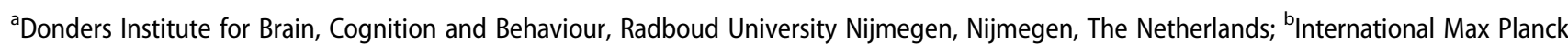 \\ Research School (IMPRS) for Language Sciences, Nijmegen, The Netherlands; ' ${ }^{\text {Max }}$ Planck Institute for Psycholinguistics, Nijmegen, The \\ Netherlands; ${ }^{\mathrm{d}}$ NHTV Breda University of Applied Science, Academy for Leisure, Breda, The Netherlands; ${ }^{\mathrm{D}}$ Department of Psychology, University \\ of York, Heslington, York, UK
}

\begin{abstract}
The current electroencephalography study investigated the relationship between the motor and (language) comprehension systems by simultaneously measuring mu and $\mathrm{N} 400$ effects. Specifically, we examined whether the pattern of motor activation elicited by verbs depends on the larger sentential context. A robust N400 congruence effect confirmed the contextual manipulation of action plausibility, a form of semantic congruency. Importantly, this study showed that: (1) Action verbs elicited more mu power decrease than non-action verbs when sentences described plausible actions. Action verbs thus elicited more motor activation than non-action verbs. (2) In contrast, when sentences described implausible actions, mu activity was present but the difference between the verb types was not observed. The increased processing associated with a larger $\mathrm{N} 400$ thus coincided with mu activity in sentences describing implausible actions. Altogether, context-dependent motor activation appears to play a functional role in deriving context-sensitive meaning.
\end{abstract}

\section{ARTICLE HISTORY}

Received 18 December 2015

Accepted 4 March 2016

\section{KEYWORDS}

Embodied language; sentence processing; mu oscillations; N400 ERP; action verb processing

\section{Introduction}

Research on the semantic representation of words indicates that brain areas involved in action and perception are co-activated during word retrieval (for a review, see Meteyard, Rodriguez Cuadrado, Bahrami, \& Vigliocco, 2012; see other contributions in this issue). These areas therefore contribute to the meaning of words, sentences, and discourse interpretation, as posited in embodied theories of language (ETLs; e.g. Barsalou, 1999, 2008; Gallese \& Lakoff, 2005; Glenberg \& Kaschak, 2002; Pulvermüller \& Fadiga, 2010; Zwaan, 2003). For example, "grasp" activates some of the neural areas involved in planning and performing everyday grasping actions (e.g. Hauk, Johnsrude, \& Pulvermüller, 2004; Rueschemeyer, Brass, \& Friederici, 2007), whereas "red" activates parts of the neural visual pathway (van Dam, van Dijk, Bekkering, \& Rueschemeyer, 2012; Simmons et al., 2007). Likewise, "kick", "pick", and "lick" activate leg, arm, and face areas, respectively (Hauk et al., 2004; see also Aziz-Zadeh, Wilson, Rizzolatti, \& lacoboni, 2006; Tettamanti et al., 2005; Willems, Labruna, D'Esposito, Ivry, \& Casasanto, 2011). In summary, the general involvement of sensorimotor areas in language comprehension is well-documented, yet it remains unclear precisely how the activation of modality-specific information relates to language comprehension.
Although all ETLs claim that conceptual knowledge activates modality-specific information, their stance differs on the functional significance of this activation (Meteyard et al., 2012). Some theorists contend that the activation of modality-specific areas during language comprehension reflects how lexical-semantic knowledge is stored in the brain: words become meaningful through fast and automatic re-enactment of perceptual states that were experienced in conjunction with hearing a specific word form (Pulvermüller, 1999, 2002, 2012; Pulvermüller \& Fadiga, 2010). Others assert that the link between modality-specific brain areas and language is tenuous at best (e.g. Mahon \& Caramazza, 2008). Reenactments of previous experiences may occur after one has actually comprehended the language content: language comprehension results in some form of simulation rather than being the result of simulation. The functional significance of modality-specific activation thus requires further investigation.

Research on the time course of modality-specific activation shows that such activation is quickly engaged upon word recognition (e.g. Amsel, 2011; Amsel, Urbach, \& Kutas, 2013; Boulenger et al., 2006). The rapid availability of motoric information has been taken as support for the integral role that modality-specific activation plays in a word's representation. Still, the

CONTACT Kevin J. Y. Lam $\otimes$ Kevin.Lam@mpi.nl

(c) 2016 Informa UK Limited, trading as Taylor \& Francis Group 
mere activation of the motor system does not fully describe its role in deriving meaning. Rather, a functional description of motor activation during language comprehension should show how the brain uses the motor system, if at all, to arrive at some interpretation when reading about actions. A meaningful description about the interaction between language and motor areas of the brain depends on such demonstrations.

Our study takes a different look at the interaction between the motor system and language processing using a contextual manipulation of motoric plausibility. Studies showing motor activation typically provide contexts that are motorically plausible (e.g. "The girl/duck swims in the pond." in van Elk, van Schie, Zwaan, \& Bekkering, 2010). Others present stimuli with little context, as in single-word processing (e.g. Pulvermüller, Härle, \& Hummel, 2001). Demonstrating motor activation in response to reading about plausible actions is not too surprising when "the default posture of our conceptual system is to be engaged with the sensorimotor system" (Mahon, 2015). When a sentence describes motoric content, the resultant motor activation reflects its meaning. Likewise, a non-motoric description results in less or no motor activation. To illustrate, idiomatic phrases like "kick the bucket" do not elicit the motor activation that is observed for phrases like "kick the ball", because the former context suggests a less motoric interpretation, an interpretation that cannot be taken literally (Raposo, Moss, Stamatakis, \& Tyler, 2009; but see Boulenger, Hauk, \& Pulvermüller, 2009). Similarly, morphologically complex German verbs ("begreifen", to comprehend) that contain a motor stem ("greifen", to grasp) also do not elicit motor activation (Rueschemeyer et al., 2007). These context-dependent effects do highlight that the meaning of a word is an emergent property, tailored according to what needs to be understood (Federmeier \& Laszlo, 2009; Kutas \& Federmeier, 2011). Thus, the action plausibility manipulation offers a unique test of the motor system's functional role, because implausible actions do not have meaning in the strictest sense. However, in order to arrive at that interpretation, the meaning of the words within the context must first be derived. In this regard, the differences in motor activation are expected between contexts describing plausible and implausible actions.

Context-dependent activation can be seen clearly in studies making explicit use of a particular conceptual attribute for a given task. In one such study (Hoenig, Sim, Bochev, Herrnberger, \& Kiefer, 2008), participants judged the semantic fit of a visually presented word referring to either a visual or an action attribute with a subsequently presented object noun (e.g. "elongated" for a knife, or "round" for an orange). The processing of natural objects and artefacts places different emphasis on visual and action attributes. In result, an attribute is more or less dominant for the processing of a given object. The most striking observation is that the brain area corresponding to a less dominant feature (e.g. the elongated shape of a knife) shows a higher level of activation when it is task-relevant. In other words, bringing the feature into focus elicits more activation of the relevant area. This finding highlights the flexible recruitment of modality-specific brain areas for current goals. Complementary electroencephalogram (EEG) measures showed that these effects occur early. A recent functional magnetic resonance imaging (fMRI) study (van Dam et al., 2012) further showed that similar effects can be observed even for objects with dominant action and visual features (e.g. the colour and shape of a tennis ball). Altogether, the studies using verbs and nouns in different contexts suggest that the brain makes efficient use of the necessary neural structures according to the contextual demands.

Crucially, the motor activation patterns to plausible and implausible action contexts are key to describing the function of the motor system. On the one hand, theories that posit that motor activation per se reflects context-independent meaning will predict activation patterns conform to the word's meaning. The function of the motor system is thus restricted to a minimal representation of the lexical meaning. On the other hand, theories that make allowance for context-dependent motor activation will predict patterns differently. If the motor system functions as an active component in deriving meaning, motor activation in an implausible action context will not reflect lexical meaning but evidence of motoric assessment.

The current study assessed whether a verb's action specificity (factor: Action; levels: action vs. non-action) changes according to plausibility (factor: Plausibility; levels: plausible vs. implausible). In a plausible action context, sentences such as "The trolleys that she pushes are broken." and "The trolleys that she delivers are broken." will elicit more or less motor activation, respectively (e.g. van Dam, Rueschemeyer, \& Bekkering, 2010 for fMRI evidence). Crucially, a comparison of action specificity allowed for a clear difference in motor activation patterns. Whether such patterns persist in an implausible action context was determined using sentences such as "The trolleys that she sews are broken." and "The trolleys that she heals are broken." Moreover, readers' sensitivity to the plausibility manipulation was assessed with the N400 ERP component, an index of meaning processing.

To measure the brain's response in terms of motor activation and language comprehension, we recorded 
scalp EEG with focus on two specific signals. Firstly, $m u$ oscillations reflect on-going dynamics from the motor cortex with a clear directionality of the expected effects (e.g. Neuper, Wörtz, \& Pfurtscheller, 2006; Pfurtscheller \& Neuper, 2001; Pineda, 2005; Salenius, Schnitzler, Salmelin, Jousmäki, \& Hari, 1997; Salmelin \& Hari, 1994). In particular, motor activation shows up as a decrease in power within the mu-frequency band $(8-12 \mathrm{~Hz}$; Hari, 2006). However, unlike posterior alpha effects that also occur within the same frequency band and have been associated with attentional and visual processing (e.g. Bastiaansen \& Brunia, 2001; Klimesch, Sauseng, Hanslmayr, Gruber, \& Freunberger, 2007), the topography of $m u$ effects occurs around central sites. The locus specificity of the predicted effects thus prevents conflation and more importantly, directs discussion of the results to a motoric interpretation. Moreover, a previous report by van Elk et al. (2010) showed that motor activation elicited by linguistic stimuli can indeed be measured using mu oscillations (also see Moreno, de Vega, \& León, 2013; Moreno et al., 2015; Vukovic \& Shtyrov, 2014).

Secondly, the N400 component is a negative deflection that is maximal over central sites around 400 ms postword onset (Kutas \& Hillyard, 1980, 1984). For example, a larger N400 component appears when a sentence ends with an incongruent word relative to a congruent one ("She spread her bread with socks/butter"). The N400 congruence effect is the difference of the N400 amplitude between the two sentences, thus a measure of comprehension (for a review, see Kutas \& Federmeier, 2011). Various theories have been put forward to interpret the N400, ranging from pre-lexical (e.g. Deacon, Dynowska, Ritter, \& Grose-Fifer, 2004) to post-lexical (integration; e.g. Hagoort, Baggio, \& Willems, 2009), or somewhere in between (e.g. Lau, Phillips, \& Poeppel, 2008; also see Brouwer, Fitz, \& Hoeks, 2012; Frenzel, Schlesewsky, \& Bornkessel-Schlesewsky, 2011). Regardless, the $\mathrm{N} 400$ is a robust finding that reflects the process of meaning access and is thus a reliable index for tracking such activity. The dual-view approach of simultaneously measuring online indices of comprehension processes ( $\mathrm{N} 400)$ and motor activity ( $\mathrm{mu}$ ) during sentence processing can hence help elucidate the interaction between language and motor areas with greater precision.

Firstly, we predicted that action verbs will elicit more motor activation relative to non-action verbs describing plausible actions; that is, a larger decrease in mu power for action verbs than non-action ones (e.g. "pushes" vs. "delivers"). Secondly, we predicted a main effect of Plausibility: an N400 congruence effect in the form of a larger negative-going $\mathrm{N} 400$ component to verbs in an implausible context relative to verbs in a plausible one (e.g. "The trolleys that he sews..." vs. "The trolleys that he pushes ..."). Thirdly, we explored the pattern of motor activation to verbs in sentences describing implausible actions (e.g. "The trolleys that he sews ..." and "The trolleys that he heals ... ") by formulating two conditional predictions: (1) a main effect of Action is predicted if motor activation of the verb per se is context-independent. Thus, mu patterns will reflect the verb's action specificity regardless of plausibility (for suggestive behavioural evidence, see Marino, Gallese, Buccino, \& Riggio, 2012) and (2) a Plausibility by Action interaction is predicted if context modulates the pattern of motor activation elicited by verbs (e.g. van Dam et al., 2012; Hoenig et al., 2008). Thus, mu patterns will reflect the verb's action specificity only in sentences describing plausible actions.

\section{Materials and methods}

\section{Participants}

Twenty-nine healthy right-handed native speakers of Dutch between ages 18 and 28 years ( 20 females; mean age $=20.6$ years) participated in exchange for course credit or monetary compensation. All participants had normal or corrected-to-normal vision and provided their informed consent. This study was approved by the local Nijmegen Ethical Committee of the Faculty of Social Sciences (ECG2012-2711-05).

After excluding participants with excessive movement artefacts, we conducted the following analyses on the remaining 25 participants ( 21 females; mean age $=20.8$ years), all of whom performed with a mean accuracy of 95\% on catch trials (mean RT $=1109 \mathrm{~ms}$ ).

\section{Stimulus materials}

We created 84 sentence stimuli, each containing a verb belonging to one of four experimental conditions (21 items per condition). Each Dutch sentence stimulus contained an object noun in the second position and the critical verb in the fifth; sentences were between seven and nine words long. We avoided wrap-up effects in the ERPs by not placing the verb at the end of the sentence (Hagoort, Brown, \& Osterhout, 1999).

The four experimental conditions were as follows (see Table 1 for examples of each): Plausible Action Verb, Plausible Non-Action Verb, Implausible Action Verb, and Implausible Non-Action Verb. To clarify, Plausibility refers to a manipulation of semantic congruency that described an action that could be performed or not. Action Verb refers to a verb that defines the action to be performed on the objects (i.e. pushing trolleys refers to the act of extending both arms slightly in front of the body). In contrast, a Non-Action Verb does a poor 
Table 1. Example stimuli of the four conditions in Dutch with English translations provided.

\begin{tabular}{|c|c|}
\hline $\begin{array}{l}\text { Plausible } \\
\text { Action Verb }\end{array}$ & $\begin{array}{l}\text { De winkelkarretjes/kinderwagens/maaiers/deuren die hij } \\
\text { wegduwt zijn gebroken. } \\
\text { The trolleys/strollers/lawnmowers/doors that he pushes } \\
\text { (away) are broken. }\end{array}$ \\
\hline $\begin{array}{l}\text { Plausible } \\
\quad \text { Non-Actior }\end{array}$ & $\begin{array}{l}\text { De winkelkarretjes/kinderwagens/maaiers/deuren die hij } \\
\text { levert zijn gebroken. }\end{array}$ \\
\hline Verb & wnmowers/doors that he delivers \\
\hline $\begin{array}{r}\text { Implat } \\
\text { Acti }\end{array}$ & $\begin{array}{l}\text { retjes/kinderwagens/maaiers/deuren die zij } \\
\text { ijn gebroken. } \\
\text { rollers/lawnmowers/doors that she sews (on) }\end{array}$ \\
\hline $\begin{array}{l}\text { Implat } \\
\text { Nor }\end{array}$ & $\begin{array}{l}\text { elkarretjes/kinderwagens/maaiers/deuren die zij } \\
\text { st zijn gebroken. }\end{array}$ \\
\hline Ver & $\begin{array}{l}\text { The trolleys/strollers/lawnmowers/doors that she heals are } \\
\text { broken. }\end{array}$ \\
\hline
\end{tabular}

Note: Critical verbs are in bold type.

job at defining the action (e.g. one can deliver trolleys by transporting them in a truck, shipped by cargo, etc.). A separate group of participants $(n=10)$ that did not participate in the EEG experiment provided ratings for each condition on semantic congruency and action specificity, confirming the intended manipulations.

Each condition contained 21 sentences. We used nonparticle verbs like "levert" ("delivers") primarily, but to reduce the variation in word length, particle verbs like "weg + duwt" ("pushes away") were also used; a previous study reported that particle verbs are processed as a single lexical unit (Cappelle, Shtyrov, \& Pulvermüller, 2010). Verbs were matched for length and frequency based on SUBTLEX-NL (Keuleers, Brysbaert, \& New, 2010; see Table 2), and each verb was paired with four different object nouns to reduce systematic effects due to nouns such as word frequency, word length, familiarity, and cloze probability. Participants only read one pair of the four possible combinations; no stimuli were repeated.

Because the $\mathrm{N} 400$ component is sensitive to differences in frequency, we avoided making comparisons in the following cases where frequency could not be matched: Plausible Action Verb and Plausible NonAction Verb, and Implausible Action Verb and Implausible Non-Action Verb.

After the experiment, participants rated all sentences for semantic congruency, action specificity, and imageability. The order of their ratings was counterbalanced. The statistical results confirmed our manipulations of

Table 2. Mean length and frequency of verbs in each experimental condition (standard deviation in parentheses).

\begin{tabular}{lcccc}
\hline & $\begin{array}{c}\text { Plausible } \\
\text { Action } \\
\text { Verb }\end{array}$ & $\begin{array}{c}\text { Plausible } \\
\text { Non-Action } \\
\text { Verb }\end{array}$ & $\begin{array}{c}\text { Implausible Action } \\
\text { Verb }\end{array}$ & $\begin{array}{c}\text { Implausible } \\
\text { Non-Action } \\
\text { Verb }\end{array}$ \\
\hline Length & $7.4(1.9)$ & $7.6(1.6)$ & $7.0(1.5)$ & $7.1(1.6)$ \\
Frequency & $1.8(0.8)$ & $2.3(0.7)$ & $1.5(0.8)$ & $2.1(0.4)$ \\
\hline
\end{tabular}

Table 3. Mean sentence ratings for Semantic Congruency, Action Specificity, and Imageability on a 5-point Likert scale (e.g. "Does the sentence clearly describe a particular action to perform?" 1 = No, not at all, $5=$ Yes, absolutely).

\begin{tabular}{lcccc}
\hline & $\begin{array}{c}\text { Plausible } \\
\text { Action } \\
\text { Verb }\end{array}$ & $\begin{array}{c}\text { Plausible } \\
\text { Non-Action } \\
\text { Verb }\end{array}$ & $\begin{array}{c}\text { Implausible } \\
\text { Action } \\
\text { Verb }\end{array}$ & $\begin{array}{c}\text { Implausible } \\
\text { Non-Action } \\
\text { Verb }\end{array}$ \\
\hline $\begin{array}{c}\text { Semantic } \\
\text { Congruency }\end{array}$ & $4.18(0.4)$ & $4.16(0.5)$ & $1.53(0.4)$ & $1.51(0.6)$ \\
$\begin{array}{c}\text { Action } \\
\text { Specificity }\end{array}$ & $4.24(0.4)$ & $2.20(0.4)$ & $4.13(0.3)$ & $2.04(0.6)$ \\
Imageability & $4.39(0.3)$ & $4.29(0.4)$ & $1.81(0.5)$ & $1.63(0.6)$ \\
\hline
\end{tabular}

Note: Standard deviation is given in parentheses.

semantic congruency and action specificity (see Table 3). We also collected imageability ratings as an additional measure.

\section{Procedure}

A practice block of 10 trials similar to the experimental stimuli was first administered and repeated when necessary. Each participant read 94 sentences across 2 blocks: 47 trials per block, of which the first 5 were dummy trials similar to critical items. The order of the sentences was pseudo-randomised so that no more than three consecutive trials were from the same condition. As a result, four experimental lists were generated using the Latin square design and randomly assigned to participants. Twenty catch trials ensured participants attended to each word of the sentence. Every three to five trials, participants responded with a button press using their index fingers (right button for "yes", left button for "no") to indicate whether or not they saw the displayed word in the preceding sentence.

Participants sat approximately $80 \mathrm{~cm}$ away from the computer screen in a dimly lit sound- and electricallyshielded booth. We presented the sentence stimuli using a PC running Presentation software (Neurobehavioural Systems, Albany, NY, USA). Button presses by the index fingers of each hand were recorded by means of a response box placed under each hand. We displayed each word at the centre for $350 \mathrm{~ms}$, followed by a blank screen for another $350 \mathrm{~ms}$, yielding a 700 ms presentation duration per item. The last word of the sentence was presented together with a period. On catch trials, the sentence was followed by a memory probe which remained on the screen until participants responded. Trials were separated by an asterisk at the centre for $3000 \mathrm{~ms}$ and we encouraged participants to blink only during this time. Words were presented on a black background using a white Arial font with size 20 . Each of the two blocks lasted approximately 20 minutes. The total duration of a session was approximately two hours including set-up and clean-up. 


\section{Recording}

We recorded the EEG from 60 active electrodes placed in an actiCAP (Brain Products $\mathrm{GmbH}$, Munich, Germany), as used in van Elk et al. (2010). The electrode positions conform to the M-10 Equidistant 61-Channel-Arrangement (i.e. an inter-electrode distance of $37 \pm 3 \mathrm{~mm}$ given a head circumference of $58 \mathrm{~cm}$ ). During recording, electrodes were referenced to the left mastoid but rereferenced offline to the average of left and right mastoids. We kept impedance levels below $10 \mathrm{k} \Omega$ and used two 32-channel BrainAmp DC EEG amplifiers to amplify the signals. The EEG and electrooculography (EOG) signals were sampled at $500 \mathrm{~Hz}$ with a $100 \mathrm{~Hz}$ high cutoff filter and a $10 \mathrm{~s}$ time constant.

\section{Analysis}

We analysed the EEG data in Brain Vision Analyzer (Brain Products $\mathrm{GmbH}$, Munich, Germany) and in Matlab 7.10 (MathWorks, Natick, MA, USA) using the FieldTrip open source toolbox (Oostenveld, Fries, Maris, \& Schoffelen, 2011). Importantly, we analysed both the $\mathrm{N} 400$ and $m u$ signals on the verb (1) because, having encountered the object- and agent-nouns, the verb represents the first moment at which sufficient information is available to establish whether an action is plausible or not to elicit an N400 congruence effect, and (2) because we were interested in whether concurrent motor activation occurs at this point to directly relate it to the $\mathrm{N} 400$ effect. The EEG segments were made from -1400 to $1400 \mathrm{~ms}$ relative to the verb onset. We removed artefacts using a semi-automatic visual inspection procedure. The number of remaining trials per condition (out of a possible total of 525) was as follows: Plausible Action Verb: 501; Implausible Action Verb: 488; Plausible Non-Action Verbs: 503; Implausible Non-Action Verb: 499.

For the time-frequency (TF) analysis, we used a 500 ms Hanning window with a $3 \mathrm{~Hz}$ frequency-smoothing window to compute power changes in frequency steps of $2 \mathrm{~Hz}$ and time steps of $10 \mathrm{~ms}$. After acquiring the TF representations for single trials, we averaged the power estimates over trials; this was done for each condition at the subject-level. Then, we calculated the mean $m u$ power between 8 and $12 \mathrm{~Hz}$ on the basis of the literature and our data set. To compare the $m u$ and the N400 effects, we used the $300-500 \mathrm{~ms}$ time window. The resulting subject-averaged power changes in the postverb onset interval were expressed as an absolute change from the baseline interval (from -150 to $0 \mathrm{~ms}$ ). For the event-related potential (ERP) analysis, we applied a baseline correction to each trial from -150 ms to verb onset. Then, to obtain the N400 ERP, we calculated the mean amplitude per condition between 300 and $500 \mathrm{~ms}$ after verb onset.

We made statistical comparisons between conditions by using a cluster-based random permutation test (Maris \& Oostenveld, 2007). This approach controls the Type I error rate in a situation involving multiple comparisons. The cluster-based random permutation test controls for interactions between time points, electrodes, and frequency bins by identifying clusters of significant differences between conditions in the fixed TF window (300-500 ms, 8-12 Hz). The procedure for the TF analysis is briefly described below. The procedure for the ERP analysis is similar except that we look for changes in the time and space dimensions.

First, for every data point (electrode by time by frequency) of two conditions, a simple dependent samples $t$ test is performed (giving uncorrected $p$ values). All data points adjacent in the three dimensions exceeding a pre-set significance level $(5 \%)$ are grouped into clusters. For each cluster, the sum of the $t$ statistics is used in the cluster-level test statistic. Next, a null distribution that assumes no difference between conditions is created. This distribution is obtained by randomly assigning the conditions 1000 times in every participant's data and calculating the largest cluster-level statistic for each randomisation. Finally, the actual observed cluster-level test statistics are compared against the null distribution, and clusters falling in the highest or lowest 2.5th percentile are considered significant.

\section{Results}

\section{TF analyses: mu power reflects motor activation to verbs}

There was no main effect of Congruency (no clusters found), indicating that $m u$ activity was not sensitive to the manipulation of plausibility. A main effect of Action approached significance (cluster statistic $=-6.24$; $p=.06$ ), indicating larger $m u$ activity for Action Verbs relative to Non-Action Verbs when collapsed across Plausibility. Importantly, in line with the prediction that motor activation should reflect both a sensitivity to action plausibility as well as differences in verb action specificity, we observed a statistically reliable Plausibility $\times$ Action interaction (cluster statistic $=-155.61$; $p=.028$ ).

In the Plausible context, Action Verbs elicited more mu power decrease between 300 and $500 \mathrm{~ms}$ after verb onset relative to Non-Action Verbs, as indicated by a statistically significant cluster (cluster statistic $=$ $-41.03 ; p=.034$; see left side of Figure 1). This effect was slightly right-lateralised around the central scalp 
region, as expected for mu effects, and thus ruling out influences of posterior alpha. In contrast, in the Implausible context, Action and Non-Action Verbs did not statistically differ in mu power (no clusters found; see right side of Figure 1). The presence of $m u$ activity in both conditions, as depicted in the time frequency representations, indicates that motor activation was involved during the processing of both sets of sentence stimuli. The previous analyses were also repeated using the time window $100-300 \mathrm{~ms}$ to determine if these effects were already present; none of the comparisons yielded any clusters.

\section{ERP analyses: N400 effect reflects differences in action plausibility}

Between 300 and $500 \mathrm{~ms}$ after verb onset, verbs in the Implausible context elicited a larger N400 negativity relative to verbs in the Plausible context (Figure 2, left). The statistically significant cluster (cluster statistic $=-1653.4$, $p=.043$ ) showed a centro-parietal distribution commonly reported for $\mathrm{N} 400$ effects (Figure 2, right; Kutas \& Hillyard, 1980, 1984). Also, we did not observe a statistically significant Plausibility $\times$ Action interaction (cluster statistic $=471.87, p=.121$ ) indicating that the N400 measure was sensitive only to the manipulation of plausibility, as predicted.

\section{Discussion}

The current study assessed the relationship between the motor and (language) comprehension systems by simultaneously measuring $m u$ and N400 effects. Specifically, we investigated whether the pattern of motor activation elicited by verbs depends on the larger sentential context. A robust $\mathrm{N} 400$ congruence effect confirmed our contextual manipulation of action plausibility. Beyond this, two main results can be taken from this study: (1) Action verbs elicited more mu power decrease than non-action verbs when sentences described plausible actions. This result confirms that action verbs elicited more motor activation than non-action verbs. (2) In

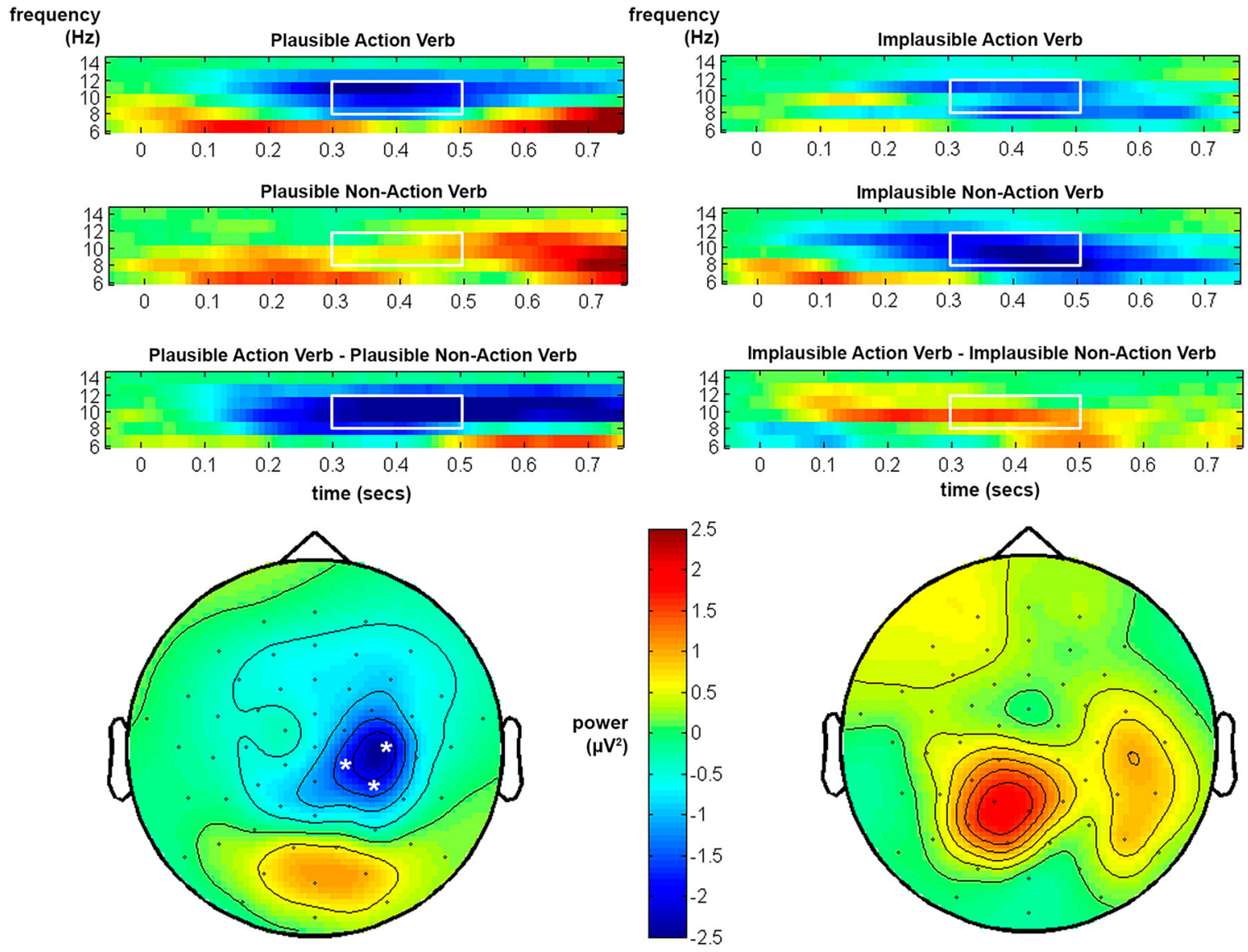

Figure 1. TF representations for the four conditions and the two main comparisons measured on the critical verbs. The averaged channels representing the effects in the TF representations are indicated with asterisks. Boxed area indicates the time window (300-500 ms) used to calculate power differences for the mu-frequency band (8-12 Hz). Difference topographies for the two comparisons are shown at bottom for these time and frequency windows. 

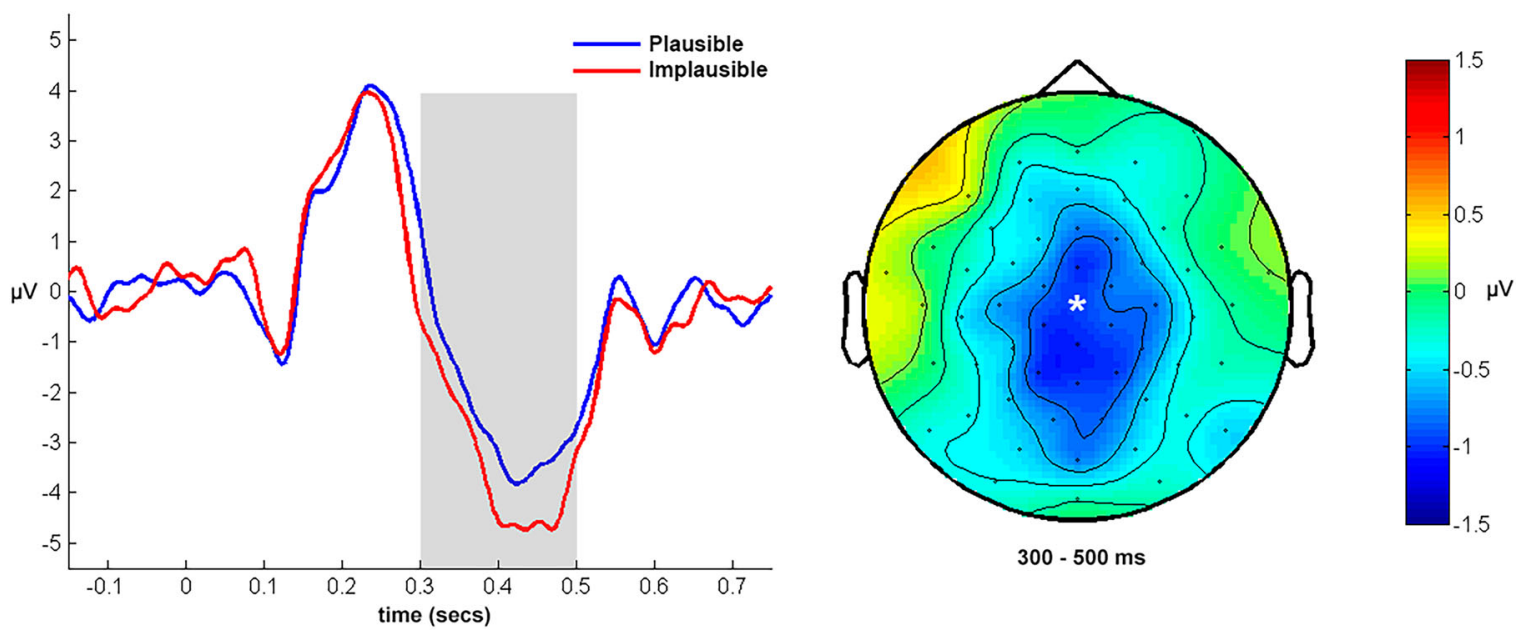

Figure 2. Left: Mean amplitude waveforms for the Plausible and Implausible conditions measured on the critical verbs of a representative channel indicated with an asterisk on difference topography plot. Negative values are plotted downwards. Shaded area indicates the time window (300-500 ms) used in analyses. Right: Difference topography.

contrast, when sentences described implausible actions, $m u$ activity was present but the difference between the verb types was not observed. The increased processing associated with a larger N400 thus coincided with mu activity in sentences describing implausible actions. Context-dependent motor activation appears to play a functional role in deriving context-sensitive meaning.

Verbal descriptions of implausible actions led to motor activation rather than an absence of it. This observation underscores how the brain makes use of available resources to make sense of input lacking plausibility. A recent behavioural study (Marino et al., 2012) demonstrated evidence of simulation (and thus motor activation) in sensibility judgements of implausible actions. Participants determined whether visually presented verbs and nouns in Italian formed a sensible pair (e.g. "to sign the cheque" vs. "to squeeze the sunset"). Verbs also differed by specificity in terms of degrees of freedom (DoF), similar to our manipulation of action specificity. In line with our results, there was a difference in the processing of these two verb types; RTs were faster to low relative to high DoF verbs. The finding suggested a difference in time course of processing for the two verb types. Low DoF verbs elicited not only the implied actions but also the corresponding set of objects on which the actions can be applied. Thus, the subsequent processing of the object noun was facilitated or made unnecessary. Notably, both sensible and non-sensible pairs yielded the RT advantage for low DoF verbs, indicating that simulation was also part of processing nonsensible content. Our study provides converging evidence that motor activation does play a functional role in making sense of linguistic input regardless of plausibility. However, action-specific and non-specific verbs do not show different time courses as measured directly on the verb.

Motor activation also occurs when attempting to process pseudo-verbs in an action-setting context (Experiment 2; Aravena et al., 2014). In terms of a "situation model" - a mental scene incorporating various pieces of information to represent the described event (Van Dijk \& Kintsch, 1983; Zwaan \& Madden, 2004; Zwaan \& Radvansky, 1998) - the authors construed motor activation during pseudo-verb processing as the on-going attempt to yield coherence. A preceding phrase functioned to set up an action context followed by a target action, non-action, or pseudo-verb (e.g. "With his black pen, Paul signs the contract.", "With his black pen, Paul plans to sign the contract.", and "With his black pen, Paul griles the contract.", respectively). In the given example, the context guided participants towards the most plausible action associated with using a pen. Encountering either an action or non-action verb completes the situation model. Accordingly, action verbs elicited a significant increase in grip-force amplitudes, whereas nonaction verbs showed otherwise. A pseudo-verb, however, does not fulfil the expectation nor provide sufficient evidence to discount it. Nonetheless, pseudo-verbs showed an activation profile similar to that found for action verbs; that is, the underspecified situation model is maintained through motor activation. The demonstration of sustained motor activity as a means to find coherence finds support in the current study. The concurrent measures of $\mathrm{N} 400$ and mu presented here go further to show the online interaction between semantic processing and motor activation.

Furthermore, the functional use of motor activation during attempts to derive meaning provides an 
alternative explanation for the results of a previous $m u$ study. A sentence-reading study in Dutch (van Elk et al., 2010) showed more motor activation for actions performed by an animal than by a human (e.g. "The duck/girl swims in the pond."). The result contradicts the embodied view in that actions performed by humans should be the easiest to understand. At least part of the explanation relates to the high cloze probability between the animal-noun and the upcoming verb, as offered by the authors. The relatively limited motor repertoire of animals limits the scope of possible actions to ease the understanding of such descriptions. We propose, however, that unfamiliarity with a nonhuman body, and consequently the action performed by that said body, limits the reader's ability to understand easily. As the mu evidence suggests, readers resort to motor activation to derive meaning.

Across different descriptions of implausible actions, readers recruit the motor system to generate an interpretation of the input. Contrary to a theoretical position that non-motoric meaning obviates motor activation, motor activation indeed serves as a mechanism to derive meaning, even if in the end, no plausible meaning is available. There are clearly many instances in which the literal interpretation of individual words and phrases is anomalous, yet the utterance is meaningful due to linguistic context and societal norms (e.g. reading figurative language such as "cry me a river", see review by Coulson (2006); or processing the description of imaginary events, such as peanuts falling in love, see Nieuwland \& Van Berkum, 2006). If the brain were to prematurely dismiss such anomalous input, comprehension would be severely disrupted. A language comprehension system that maintains different possible interpretations for a longer time is well-suited to a generative human language. We therefore propose that the motor system serves a functional role in deriving meaning. In the current and cited studies, reading about implausible actions leads readers to recruit the motor system to try to enact the implied action or entertain alternatives.

The current study suggests that there is a functional role for motor activation in deriving context-sensitive meaning. Online sentence processing yielded highly specific patterns of motor activation implied by the verb and the embedded context. The concurrent measure of meaning processing (N400) and motor activation $(\mathrm{mu})$ further revealed that reading descriptions of implausible actions coincided with motor involvement. Thus, motor activation not only reflected the meaning of words, but it also served as a means to derive meaning. This dual-view on motor activation during online language processing opens up a new approach to investigate how motor activation contributes to meaning. Future studies may consider other functional contributions of the motor system to comprehension. Comparing motor activation patterns across tasks can clarify the relative involvement of motor activation in fulfilling various task demands (e.g. Hauk \& Tschentscher, 2013; Louwerse, Hutchinson, Tillman, \& Recchia, 2015; Willems \& Casasanto, 2011). Other ways of showing modulations of $m u$ oscillations to other types of motor meaning can expand its scope of use (e.g. Moody \& Gennari, 2010, on implied physical effort by which greater or lesser effort might be expected to modulate $m u$ accordingly).

\section{Conclusions}

When people read action verbs, the motor system becomes activated (e.g. Kemmerer \& Gonzalez-Castillo, 2010; Pulvermüller, 1999, 2002, 2012). In sentences describing plausible actions, motor activation reflects the verb's meaning. Verbs with more action specificity elicited more motor activation, as shown by a larger mu power decrease with action verbs than with nonaction verbs. Moreover, motor activation is also sensitive to context (in particular, action plausibility). Rather than a lack of motor activation, action and non-action verbs in sentences describing implausible actions elicited comparable mu power decreases. The reader's effort in processing implausible actions shows the flexible interaction between the language and motor areas (for a review, see Kiefer \& Pulvermüller, 2012; also see Mahon, 2015) and highlights one mechanism that is used during sentence comprehension. This manner of interaction between language and modality-specific areas of the brain supports ETLs that predict context-sensitive motor activation when people read verbs in sentences (for reviews, see Borghi \& Cimatti, 2010; Fischer \& Zwaan, 2008).

\section{Acknowledgements}

This work was supported by a Donders Graduate School for Cognitive Neuroscience TOPTalent grant [grant number NWO 022.001.026] from the Netherlands Organisation for Scientific Research awarded to KJYL. For all technical assistance, the authors thank the Technical Support Group of the Faculty of Social Sciences Nijmegen and Sander Berends (Centre for Cognitive Neuroimaging). The authors also thank two anonymous reviewers for their constructive feedback.

\section{Disclosure statement}

No potential conflict of interest was reported by the authors. 


\section{References}

Amsel, B. D. (2011). Tracking real-time neural activation of conceptual knowledge using single-trial event-related potentials. Neuropsychologia, 49(5), 970-983. doi:10.1016/j. neuropsychologia.2011.01.003

Amsel, B. D., Urbach, T. P., \& Kutas, M. (2013). Alive and grasping: Stable and rapid semantic access to an object category but not object graspability. Neurolmage, 77, 1-13. doi:10.1016/j. neuroimage.2013.03.058

Aravena, P., Courson, M., Frak, V., Cheylus, A., Paulignan, Y., Deprez, V., \& Nazir, T. A. (2014). Action relevance in linguistic context drives word-induced motor activity. Frontiers in Human Neuroscience, 8, 163. doi:10.3389/fnhum.2014.00163

Aziz-Zadeh, L., Wilson, S. M., Rizzolatti, G., \& lacoboni, M. (2006). Congruent embodied representations for visually presented actions and linguistic phrases describing actions. Current Biology, 16(18), 1818-1823. doi:10.1016/j.cub.2006.07.060

Barsalou, L. (1999). Perceptual symbol systems. Behavioral and Brain Sciences, 22, 577-660. doi:10.1017/S0140525X99532147

Barsalou, L. W. (2008). Grounded cognition. Annual Review of Psychology, 59, 617-645. doi:10.1146/annurev.psych.59. 103006.093639

Bastiaansen, M. C., \& Brunia, C. H. (2001). Anticipatory attention: An event-related desynchronization approach. International Journal of Psychophysiology, 43(1), 91-107. doi:10.1016/ S0167-8760(01)00181-7

Borghi, A. M., \& Cimatti, F. (2010). Embodied cognition and beyond: Acting and sensing the body. Neuropsychologia, 48 (3), 763-773. doi:10.1016/j.neuropsychologia.2009.10.029

Boulenger, V., Hauk, O., \& Pulvermüller, F. (2009). Grasping ideas with the motor system: Semantic somatotopy in idiom comprehension. Cerebral Cortex, 19(8), 1905-1914. doi:10.1093/ cercor/bhn217

Boulenger, V., Roy, A. C., Paulignan, Y., Deprez, V., Jeannerod, M., $\&$ Nazir, T. A. (2006). Cross-talk between language processes and overt motor behavior in the first $200 \mathrm{msec}$ of processing. Journal of Cognitive Neuroscience, 18(10), 1607-1615. doi:10. 1162/jocn.2006.18.10.1607

Brouwer, H., Fitz, H., \& Hoeks, J. (2012). Getting real about semantic illusions: Rethinking the functional role of the P600 in language comprehension. Brain Research, 1446, 127-143. doi:10.1016/j.brainres.2012.01.055

Cappelle, B., Shtyrov, Y., \& Pulvermüller, F. (2010). Heating up or cooling up the brain? MEG evidence that phrasal verbs are lexical units. Brain and Language, 115(3), 189-201. doi:10. 1016/j.bandl.2010.09.004

Coulson, S. (2006). Constructing meaning. Metaphor and Symbol, 21(4), 245-266. doi:10.1207/s15327868ms2104_3

van Dam, W. O., van Dijk, M., Bekkering, H., \& Rueschemeyer, S.A. (2012). Flexibility in embodied lexical-semantic representations. Human Brain Mapping, 33(10), 2322-2333. doi:10. 1002/hbm.21365

van Dam, W. O., Rueschemeyer, S.-A., \& Bekkering, H. (2010). How specifically are action verbs represented in the neural motor system: An fMRI study. Neurolmage, 53(4), 13181325. doi:10.1016/j.neuroimage.2010.06.071

van Dijk, T. A., \& Kintsch, W. (1983). Strategies of discourse comprehension. New York, NY: Academic Press.

Deacon, D., Dynowska, A., Ritter, W., \& Grose-Fifer, J. (2004). Repetition and semantic priming of nonwords: Implications for theories of N400 and word recognition. Psychophysiology, 41(1), 60-74. doi:10.1111/1469-8986.00120

van Elk, M., van Schie, H. T., Zwaan, R. A., \& Bekkering, H. (2010). The functional role of motor activation in language processing: Motor cortical oscillations support lexical-semantic retrieval. Neurolmage, 50(2), 665-677. doi:10.1016/j. neuroimage.2009.12.123

Federmeier, K. D., \& Laszlo, S. (2009). Time for meaning: Electrophysiology provides insights into the dynamics of representation and processing in semantic memory. Psychology of Learning and Motivation, 51, 1-44. doi:10. 1016/S0079-7421(09)51001-8

Fischer, M. H., \& Zwaan, R. A. (2008). Embodied language: A review of the role of the motor system in language comprehension. The Quarterly Journal of Experimental Psychology, 61 (6), 825-850. doi:10.1080/17470210701623605

Frenzel, S., Schlesewsky, M., \& Bornkessel-Schlesewsky, I. (2011). Conflicts in language processing: A new perspective on the N400-P600 distinction. Neuropsychologia, 49(3), 574-579. doi:10.1016/j.neuropsychologia.2010.12.003

Gallese, V., \& Lakoff, G. (2005). The brain's concepts: The role of the sensory-motor system in conceptual knowledge. Cognitive Neuropsychology, 22(3-4), 455-479. doi:10.1080/ 02643290442000310

Glenberg, A. M., \& Kaschak, M. P. (2002). Grounding language in action. Psychonomic Bulletin \& Review, 9(3), 558-565. doi:10. 3758/BF03196313

Hagoort, P., Baggio, G., \& Willems, R. M. (2009). Semantic unification. In M. S. Gazzaniga (Ed.), The cognitive neurosciences (4th ed., pp. 819-836). Cambridge, MA: MIT Press.

Hagoort, P., Brown, C. M., \& Osterhout, L. (1999). The neurocognition of syntactic processing. In C. M. Brown \& P. Hagoort (Eds.), The neurocognition of language (pp. 273-316). Oxford: Oxford University Press.

Hari, R. (2006). Action-perception connection and the cortical mu rhythm. Progress in Brain Research, 159, 253-260. doi:10.1016/S0079-6123(06)59017-X

Hauk, O., Johnsrude, I., \& Pulvermüller, F. (2004). Somatotopic representation of action words in human motor and premotor cortex. Neuron, 41(2), 301-307. doi:10.1016/S08966273(03)00838-9

Hauk, O., \& Tschentscher, N. (2013). The body of evidence: What can neuroscience tell us about embodied semantics? Frontiers in Psychology, 4, 50. doi:10.3389/fpsyg.2013.00050

Hoenig, K., Sim, E. J., Bochev, V., Herrnberger, B., \& Kiefer, M. (2008). Conceptual flexibility in the human brain: Dynamic recruitment of semantic maps from visual, motor, and motion-related areas. Journal of Cognitive Neuroscience, 20 (10), 1799-1814. doi:10.1162/jocn.2008.20123

Kemmerer, D., \& Gonzalez-Castillo, J. (2010). The two-level theory of verb meaning: An approach to integrating the semantics of action with the mirror neuron system. Brain and Language, 112(1), 54-76. doi:10.1016/j.bandl.2008.09.010

Keuleers, E., Brysbaert, M., \& New, B. (2010). SUBTLEX-NL: A new measure for Dutch word frequency based on film subtitles. Behavior Research Methods, 42(3), 643-650. doi:10.3758/ BRM.42.3.643

Kiefer, M., \& Pulvermüller, F. (2012). Conceptual representations in mind and brain: Theoretical developments, current evidence and future directions. Cortex, 48(7), 805-825. doi:10. 1016/j.cortex.2011.04.006 
Klimesch, W., Sauseng, P., Hanslmayr, S., Gruber, W., \& Freunberger, R. (2007). Event-related phase reorganization may explain evoked neural dynamics. Neuroscience \& Biobehavioral Reviews, 31(7), 1003-1016. doi:10.1016/j. neubiorev.2007.03.005

Kutas, M., \& Federmeier, K. D. (2011). Thirty years and counting: Finding meaning in the $\mathrm{N} 400$ component of the event-related brain potential (ERP). Annual Review of Psychology, 62, 621-647. doi:10.1146/annurev.psych.093008. 131123

Kutas, M., \& Hillyard, S. A. (1980). Reading senseless sentences: Brain potentials reflect semantic incongruity. Science, 207 (4427), 203-205. doi:10.1126/science.7350657

Kutas, M., \& Hillyard, S. A. (1984). Brain potentials during reading reflect word expectancy and semantic association. Nature, 307, 161-163. doi:10.1038/307161a0

Lau, E. F., Phillips, C., \& Poeppel, D. (2008). A cortical network for semantics: (De)constructing the N400. Nature Reviews Neuroscience, 9(12), 920-933. doi:10.1038/nrn2532

Louwerse, M. M., Hutchinson, S., Tillman, R., \& Recchia, G. (2015). Effect size matters: The role of language statistics and perceptual simulation in conceptual processing. Language, Cognition and Neuroscience, 30(4), 430-447. doi:10.1080/ 23273798.2014.981552

Mahon, B. Z. (2015). What is embodied about cognition? Language, Cognition and Neuroscience, 30(4), 420-429. doi:10.1080/23273798.2014.987791

Mahon, B. Z., \& Caramazza, A. (2008). A critical look at the embodied cognition hypothesis and a new proposal for grounding conceptual content. Journal of Physiology-Paris, 102(1), 5970. doi:10.1016/j.jphysparis.2008.03.004

Marino, B. F., Gallese, V., Buccino, G., \& Riggio, L. (2012). Language sensorimotor specificity modulates the motor system. Cortex, 48(7), 849-856. doi:10.1016/j.cortex.2010.12.003

Maris, E., \& Oostenveld, R. (2007). Nonparametric statistical testing of EEG- and MEG-data. Journal of Neuroscience Methods, 164(1), 177-190. doi:10.1016/j.jneumeth.2007.03.024

Meteyard, L., Rodriguez Cuadrado, S., Bahrami, B., \& Vigliocco, G. (2012). Coming of age: A review of embodiment and the neuroscience of semantics. Cortex, 48(7), 788-804. doi:10. 1016/j.cortex.2010.11.002

Moody, C. L., \& Gennari, S. P. (2010). Effects of implied physical effort in sensory-motor and pre-frontal cortex during language comprehension. Neurolmage, 49(1), 782-793. doi:10.1016/j.neuroimage.2009.07.065

Moreno, I., de Vega, M., \& León, I. (2013). Understanding action language modulates oscillatory mu and beta rhythms in the same way as observing actions. Brain and Cognition, 82(3), 236-242. doi:10.1016/j.bandc.2013.04.010

Moreno, I., de Vega, M., León, I., Bastiaansen, M., Lewis, A. G., \& Magyari, L. (2015). Brain dynamics in the comprehension of action-related language. A time-frequency analysis of mu rhythms. Neurolmage, 109, 50-62. doi:10.1016/j.neuroimage. 2015.01.018

Neuper, C., Wörtz, M., \& Pfurtscheller, G. (2006). ERD/ERS patterns reflecting sensorimotor activation and deactivation. Progress in Brain Research, 159, 211-222. doi:10.1016/ S0079-6123(06)59014-4

Nieuwland, M. S., \& Van Berkum, J. J. (2006). When peanuts fall in love: N400 evidence for the power of discourse. Journal of Cognitive Neuroscience, 18(7), 1098-1111. doi:10.1162/jocn. 2006.18.7.1098
Oostenveld, R., Fries, P., Maris, E., \& Schoffelen, J. M. (2011). FieldTrip: Open source software for advanced analysis of MEG, EEG, and invasive electrophysiological data. Computational Intelligence and Neuroscience, 2011, article no. 1.

Pfurtscheller, G., \& Neuper, C. (2001). Motor imagery and direct brain-computer communication. Proceedings of the IEEE, 89 (7), 1123-1134. doi:10.1109/5.939829

Pineda, J. A. (2005). The functional significance of mu rhythms: Translating "seeing" and "hearing" into "doing". Brain Research Reviews, 50(1), 57-68. doi:10.1016/j.brainresrev.2005.04.005

Pulvermüller, F. (1999). Words in the brain's language. Behavioral and Brain Sciences, 22, 253-279. doi:10.1017/ S0140525X9900182X

Pulvermüller, F. (2002). The neuroscience of language: On brain circuits of words and serial order. New York: Cambridge University Press.

Pulvermüller, F. (2012). Meaning and the brain: The neurosemantics of referential, interactive, and combinatorial knowledge. Journal of Neurolinguistics, 25(5), 423-459. doi:10.1016/ j.jneuroling.2011.03.004

Pulvermüller, F., \& Fadiga, L. (2010). Active perception: Sensorimotor circuits as a cortical basis for language. Nature Reviews Neuroscience, 11(5), 351-360. doi:10.1038/nrn2811

Pulvermüller, F., Härle, M., \& Hummel, F. (2001). Walking or talking?: Behavioral and neurophysiological correlates of action verb processing. Brain and Language, 78(2), 143168. doi:10.1006/brln.2000.2390

Raposo, A., Moss, H. E., Stamatakis, E. A., \& Tyler, L. K. (2009). Modulation of motor and premotor cortices by actions, action words and action sentences. Neuropsychologia, 47 (2), 388-396. doi:10.1016/j.neuropsychologia.2008.09.017

Rueschemeyer, S.-A., Brass, M., \& Friederici, A. D. (2007). Comprehending prehending: Neural correlates of processing verbs with motor stems. Journal of Cognitive Neuroscience, 19 (5), 855-865. doi:10.1162/jocn.2007.19.5.855

Salenius, S., Schnitzler, A., Salmelin, R., Jousmäki, V., \& Hari, R. (1997). Modulation of human cortical rolandic rhythms during natural sensorimotor tasks. Neurolmage, 5(3), 221228. doi:10.1006/nimg.1997.0261

Salmelin, R., \& Hari, R. (1994). Characterization of spontaneous MEG rhythms in healthy adults. Electroencephalography and Clinical Neurophysiology, 91(4), 237-248. doi:10.1016/00134694(94)90187-2

Simmons, W. K., Ramjee, V., Beauchamp, M. S., McRae, K., Martin, A., \& Barsalou, L. W. (2007). A common neural substrate for perceiving and knowing about color. Neuropsychologia, 45(12), 2802-2810. doi:10.1016/j. neuropsychologia.2007.05.002

Tettamanti, M., Buccino, G., Saccuman, M. C., Gallese, V., Danna, M., Scifo, P., ... Perani, D. (2005). Listening to action-related sentences activates fronto-parietal motor circuits. Journal of Cognitive Neuroscience, 17(2), 273-281. doi:10.1162/ 0898929053124965

Vukovic, N., \& Shtyrov, Y. (2014). Cortical motor systems are involved in second-language comprehension: Evidence from rapid mu-rhythm desynchronisation. Neurolmage, 102, 695-703. doi:10.1016/j.neuroimage.2014.08.039

Willems, R. M., \& Casasanto, D. (2011). Flexibility in embodied language understanding. Frontiers in Psychology, 2, 116. doi:10.3389/fpsyg.2011.00116

Willems, R. M., Labruna, L., D'Esposito, M., Ivry, R., \& Casasanto, D. (2011). A functional role for the motor system in language 
understanding: Evidence from theta-burst transcranial magnetic stimulation. Psychological Science, 22(7), 849-854. doi:10. 1177/0956797611412387

Zwaan, R. A. (2003). The immersed experiencer: Toward an embodied theory of language comprehension. Psychology of Learning and Motivation, 44, 35-62. doi:10.1016/S00797421(03)44002-4
Zwaan, R. A., \& Madden, C. J. (2004). Updating situation models. Journal of Experimental Psychology: Learning, Memory, and Cognition, 30(1), 283-288. doi:10.1037/02787393.30.1.283

Zwaan, R. A., \& Radvansky, G. A. (1998). Situation models in language comprehension and memory. Psychological Bulletin, 123(2), 162. doi:10.1037/0033-2909.123.2.162 